\title{
IDENTIFICATION OF TRANSIENT PHENOMENA OCCURRING AT THE INITIATION AND TERMINATION OF WHEELSET SLIDING
}

\author{
Michael Lata ${ }^{1}$, Petr Voltr ${ }^{2}$ \\ ${ }^{1,2}$ Jan Perner Transport Faculty, University of Pardubice, Studentská 95, \\ 53210 Pardubice, Czech Republic \\ E-mails: ${ }^{1}$ michael.lata@upce.cz; ${ }^{2}$ petr.voltr@student.upce.cz (corresponding author)
}

Submitted 24 March 2011; accepted 6 May 2011

\begin{abstract}
The paper deals with adhesion experiments on an actual traction vehicle. An efficient and quite simple method was employed to detect dynamical effects occurring at the exceeding of the adhesion limit. Along with the disabled anti-slip protection system, the examined wheelset was repeatedly brought into gross sliding while acceleration was measured taking the selected components of the running gear. The experiment confirmed the assumption that the initiation and termination of sliding were accompanied by intense dynamical effects which, additionally, could be precisely identified.
\end{abstract}

Keywords: transient phenomenon, experiment, adhesion coefficient, adhesion characteristic, creepage, slip, wheel sliding.

\section{Introduction}

The issues of examining rail vehicle dynamics are extensive and include a multitude of questions. The authors deal with the issues both theoretically and experimentally; a principal matter is the matter of wheel to rail adhesion.

The questions of drive dynamics of the wheelset have appeared in the focus of attention of many authors such as - Buscher (1995), Hirotsu, Ishida (1975), Jöckel (2001), Mężyk (2002), Polach (2002), Schreiber, Kögel (1996), Spiryagin et al. (2008), Zahrádka (1976), Zeman et al. (1992), both in the field of simulation modelling and experimental measurements.

The research carried out has been based on fundamental works published, for example, in papers by Freibauer (1983), Čáp (1991), Kalker (1973, 1978), Zahrádka (1976). A comprehensive overview and the possibilities of reaching a solution are shown in papers by Lata $(2001,2008)$.

The dynamical phenomena of the oscillation of mechanical components of a rail vehicle are often nonlinear and nonsteady. Transient effects often occur and can be characterised by a short time of duration and unstable mean values.

The aim of the experiments on the traction vehicle was to show that intense dynamical effects on the running gear of a locomotive occurred when wheelset slid- ing arose and terminated, whereas in the course of the gross sliding itself, the effects were less significant. The measured data sets were subjected to spectral analysis. The experiments were to prove that strong and marked dynamical effects came in the moment of transition from effective slip into full sliding, then calmed down and appeared clearly again when adhesion was restored.

The torsional system of the wheelset drive of an electric locomotive has designed stronger or weaker kinematic coupling to components oscillating in the vertical direction. Considering older design electric locomotives produced by $\breve{S} k o d a$, coupling is strong due to the suspension of the axle gearbox. Therefore, it may be expected that dynamical transient phenomena may be identified not only in rotating parts but also in vertical oscillations. It is supposed that particularly the 1st and 2nd eigenfrequencies of the drive system (approximately $14 \mathrm{~Hz}$ and $29 \mathrm{~Hz}$ ) as well as higher frequency peaks will be recognizable in the oscillation spectrum.

The experiment involves the inducement of the transient phenomenon of the exceeding of the wheelset adhesion limit and measurements of acceleration in the components of the selected running gear. Identifying the moments of the initiation and termination of gross sliding is facilitated by the analysis of recordings obtained using a high-speed industrial camera directed of the contact between wheel and rail. 


\section{Experiments on the Locomotive}

\subsection{Preparation for Experiments}

The performed measurement was preceded by the preparation of the locomotive and measurement instrumentation. As a suitable vehicle, a four-axle directcurrent electric locomotive of $79 \mathrm{E}$, series 130 made by Škoda was chosen. A six-axle diesel-electric locomotive ČKD of series 770 was used as a braking vehicle. The experiments were carried out in dry weather on a straight track in the premises of locomotive maintenance facility in Česká Třebová, Czech Republic.

DC electric locomotive Škoda, series 130 (Fig. 1) is a four-axle locomotive with a tractive power of $2000 \mathrm{~kW}$. The mechanical part of its running gear is almost identical to that of the well-known fast train locomotive of series 150 with the power of $4000 \mathrm{~kW}$ and a maximum speed of $140 \mathrm{~km} / \mathrm{h}$ and to all Škoda locomotive series based on them. The vehicle was chosen for our experiments because of its strong kinematic coupling of rotational and vertical motions in the running gear. The axle is driven by a series direct-current motor connected rigidly with the bogie frame (Fig. 2) employing a cardan shaft situated in the hollow rotor. The axle gearbox is mounted on the axle and connected to the bogie frame by a vertical link.

Preparation for the experiment included the following stages: first, the locomotive was equipped with accelerometric sensors and the measurement chain was completed. Further, it was necessary to by-pass the antislip protection contactor and to disable pneumatic cylinders for axle load compensation. An industrial camera for recording the motion of a wheel against a rail head was set up. Another camera was placed in the driver's cab and aimed at dashboard instruments, particularly the ammeter. Measurement was carried out at the first wheelset in the direction of travel. One of the wheels was furnished with paint and reflective stripes and the side of the rail head was marked in a similar way so that relative motion could be easily identified. Accelerometric sensors were mounted to both axle boxes (signals $\ddot{x}_{11}$, $\left.\ddot{z}_{11}, \ddot{x}_{12}, \ddot{z}_{12}\right)$ and to the gearbox $\left(\ddot{z}_{n}, \ddot{z}_{p}\right)$. The layout of the sensors is indicated in Fig. 3.

The measurement chain included accelerometric sensors $\mathrm{HBM} \mathrm{B} 12 / 200 \mathrm{~Hz}$ and $\mathrm{B} 12 / 500 \mathrm{~Hz}$, data acquisition system HBM DMC Plus, a laptop with an appropriate interface and HBM Catman 32-4.5 software. The laptop also acquired image data from both cameras.

\subsection{A Course of the Experiments and Processing of the Obtained Results}

After the vehicles were coupled together, they were towed to the prepared track section. The brakes of the rear locomotive were applied, which simulated hauled weight. A series of test runs on dry track was performed; subsequently, adhesion conditions were artificially downgraded and further tests were made. In each test run, the driver was manually shifting up, which set the locomotive in motion; the motor current was increasing. When the power handle was around position 8 , dynami-

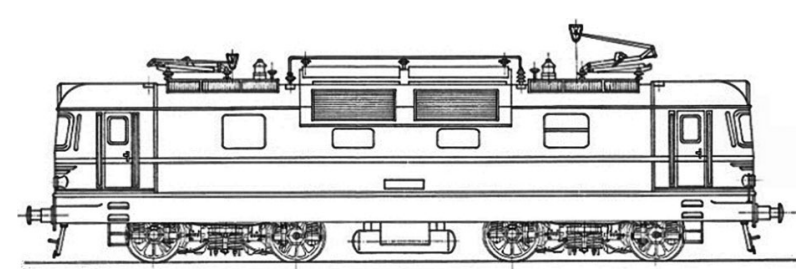

Fig. 1. A sketch of electric locomotive Škoda, series 130
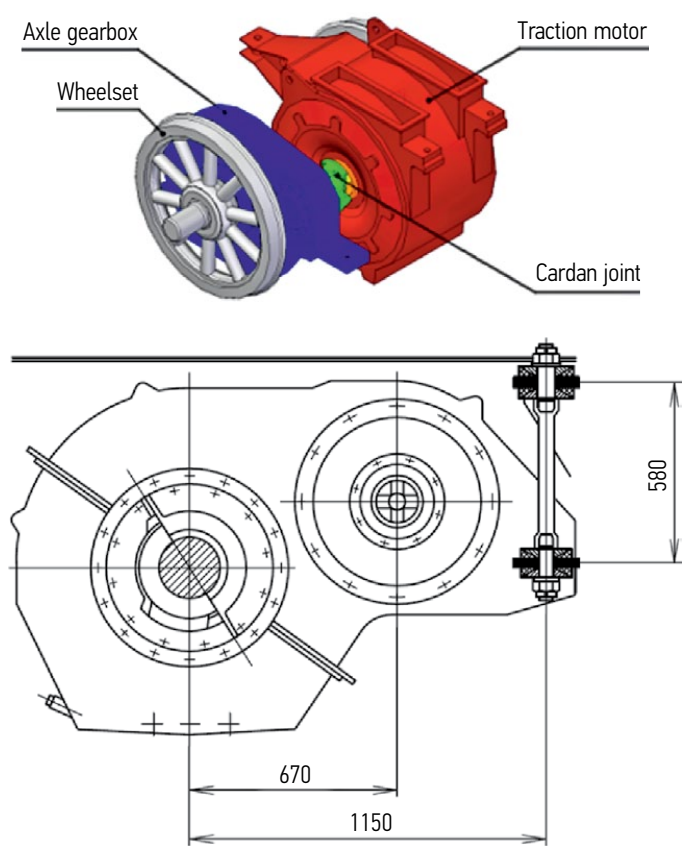

Fig. 2. The wheelset driven by a cardan shaft in a hollow rotor (top) and the suspension of the axle gearbox on the bogie frame (bottom)

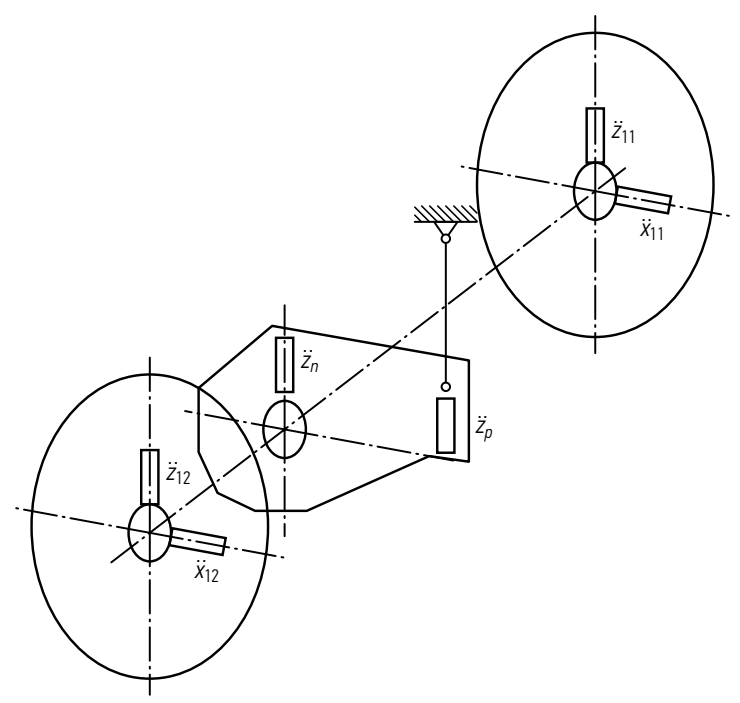

Fig. 3. The layout of accelerometric sensors on the wheelset with the symbols of the measured quantities (accelerations in the $x$ and $z$ directions)

cal effects appeared: the first wheelset was just on adhesion limit. After exceeding it, the wheelset started sliding and dynamical effects diminished. The rotational speed of the wheelset tended to increase rapidly. 
Since anti-slip protection was disabled, it was necessary to shift down without delay and brake the wheelset by direct air brake. The restoration of adhesion brought about a dynamical effect similar to that of exceeding of the adhesion limit.

The recorded data were subsequently analysed. Data files that may be browsed directly in the Catman environment were created. Further, the LabView 7.1 system, which is regularly used by the authors for signal processing, was employed. In this case, the signals were filtered by a low-pass $100 \mathrm{~Hz}$ filter since it was expected that relevant frequency ranges were situated no higher than at $60 \div 70 \mathrm{~Hz}$. Power spectral densities of acceleration were also calculated from the recorded data. At the same time, recordings from both cameras (Fig. 4) were processed in the Dewesoft environment and saved as video files. Since time is indicated in the files, the recorded motion of wheel against rail (the beginning and end of wheel slip) may be confronted with the time courses of acceleration with great accuracy.

\section{Discussion of Results}

\subsection{General Characteristics}

The measured data show that the intense development of oscillations occurs at the moments of the beginning and end of wheelset sliding. During sliding itself, the amplitude of oscillation is lower. It must be emphasized though that such dynamical effects are typical of drive design used at the examined locomotive. First, a soft characteristic of a direct-current motor with series excitation winding and a high moment of the inertia of its rotor greatly contribute to the development of significant oscillations. Second, the vertical link of the axle-mounted gearbox constitutes a relatively strong coupling of torsional and vertical motion in the running gear, wherefore these oscillations may be also observed at non-rotating parts. It may be expected that oscillation would be much lower in the components of a modern quill drive using an asynchronous AC motor and, in any case, it would not be so strongly transmitted to nonrotating parts.

\subsection{The Eigenfrequencies of the Torsional System}

As for frequency spectra, almost all recorded courses show dominant frequencies of about $14 \mathrm{~Hz}$ and $29 \mathrm{~Hz}$. The occurrence of these peaks is clearly justifiable and corresponds exactly to the eigenfrequencies calculated with reference to the theory.

A simplified calculation of the eigenfrequencies of a two-mass torsional system follows. The masses are characterized by the moments of the inertia of the wheelset $\left(J_{w}\right)$ and the rotor of the traction motor $\left(J_{r}^{\prime}\right)$. In the first step, the system is further simplified by leaving out the gears, which requires a conversion of some quantities to a single axis which is, in this case, constituted by the wheelset axis. It is necessary to convert the values of the torsional stiffness of the shaft $\left(k_{t}^{\prime}\right)$ and the moment of the inertia of the rotor. The original system is shown in Fig. 5, whereas Figs 6 and 7 indicate the equivalent

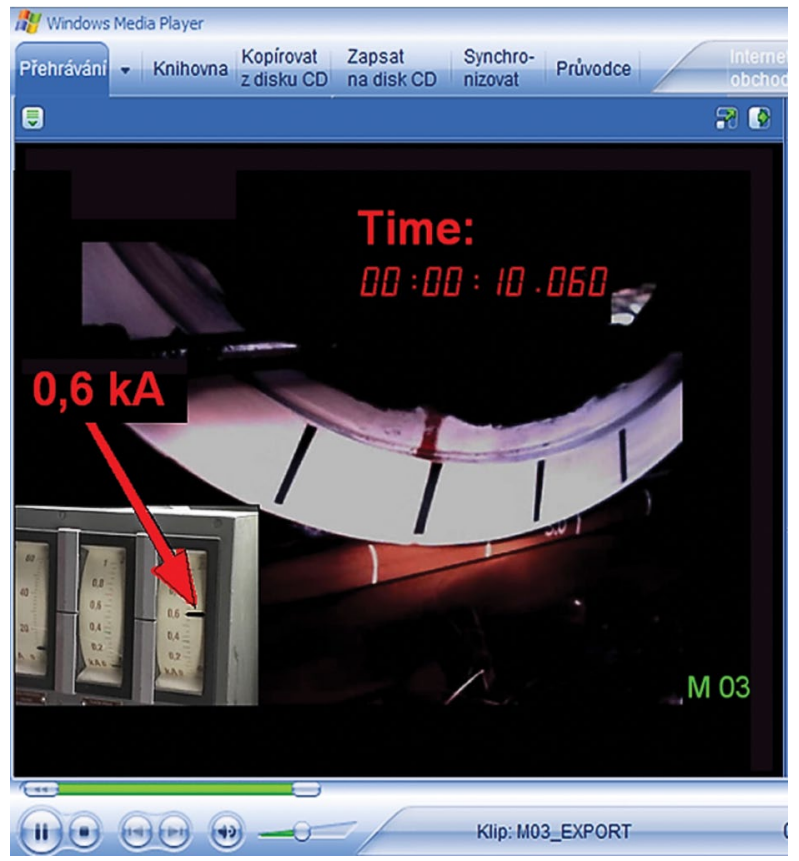

Fig. 4. The camera's view of the observed wheel and ammeters in the driver's cab recorded in the experiment numbered M03, at $10.06 \mathrm{~s}$ from the start of the test when the transient phenomenon was initiated

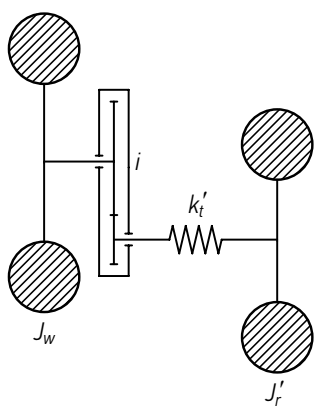

Fig. 5. The simplified torsional system of wheelset drive

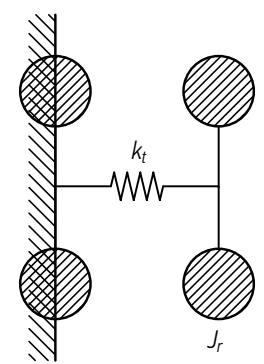

Fig. 6. The principle of determining the 1st eigenfrequency by fixing wheelset mass (the wheelset is blocked and the rotor oscillates)

system. In the original system, torsional stiffness and the moment of the inertia of the rotor are denoted as $k_{t}^{\prime}$ and $J_{r}{ }^{\prime}$ respectively, whereas $k_{t}$ and $J_{r}$ indicate quantities converted to the wheelset axis.

In a simple view, two modes can be distinguished: rigid wheelset/track fixing and unrestrained rotation. 

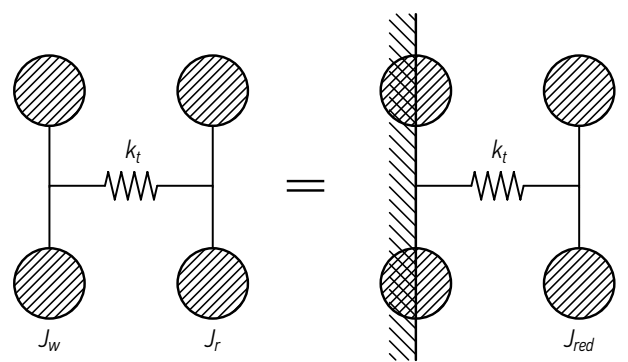

Fig. 7. The principle of determining the 2 nd eigenfrequency - the wheelset is regarded as free and both masses oscillate against each other

Further explanation may be found, e.g. in the papers by Čáp (1991) and Lata (2001). The two modes are based on the linearised adhesion characteristic. In the mode of rigid fixing, the adhesion joint constitutes a very stiff damper, the wheelset is regarded as rolling without creepage and the rotor oscillates alone. In the free rotating mode, the adhesion joint forms a very soft damper and the wheelset may rotate almost freely (neglecting friction between wheel and rail) so that the wheelset and the rotor oscillate against each other. The boundary of the modes is constituted by the peak of the linearised adhesion characteristic.

The rigid wheelset/track joint means that the wheelset is fixed to the basic frame (Fig. 6). Angular eigenfrequency may be expressed as:

$$
\Omega_{1}=\sqrt{\frac{k_{t}}{J_{t}}}[\mathrm{rad} / \mathrm{s}]
$$

and eigenfrequency in Hertz:

$$
f_{1}=\frac{1}{2 \pi} \cdot \Omega_{1}[\mathrm{~Hz}]
$$

The free rotation mode allows the two masses to oscillate against each other, which forms the second eigenmode that may be regarded as a 'series connection' where the two masses may be substituted by a single mass the moment of inertia of which is $J_{\text {red }}$ (Fig. 7). The reciprocal of the equivalent moment of inertia equals the sum of the reciprocals of the actual moments of inertia:

$$
\frac{1}{J_{\text {red }}}=\frac{1}{J_{w}}+\frac{1}{J_{r}} \text {. }
$$
lation:

The eigenfrequency of the second mode of oscil-

$$
\begin{aligned}
& \Omega_{2}=\sqrt{\frac{k_{t}}{J_{\text {red }}}}=\sqrt{\frac{k_{t} \cdot\left(J_{w}+J_{\text {red }}\right)}{J_{w} \cdot J_{\text {red }}}}[\mathrm{rad} / \mathrm{s}] ; \\
& f_{2}=\frac{1}{2 \pi} \cdot \Omega_{2}[\mathrm{~Hz}] .
\end{aligned}
$$

Taking into account the values of parameters for the locomotive $\breve{S} k o d a$ of series 130, the first eigenfrequency obtained from the formulae is $13.9 \mathrm{~Hz}$ and the second eigenfrequency is $29.9 \mathrm{~Hz}$.

\subsection{Higher Frequency Ranges}

The spectra of the recorded signals also show higher peaks of approx. $38 \mathrm{~Hz}, 43 \mathrm{~Hz}, 54 \mathrm{~Hz}, 58 \mathrm{~Hz}$ and $70 \mathrm{~Hz}$; the peaks of $43 \mathrm{~Hz}$ and $58 \mathrm{~Hz}$ are dominant in most signals. One of these frequencies is held to represent the oscillation of the gearbox itself, the second may appear due to backlash in the gear. It was not possible to measure the tooth backlash of this locomotive, however, the first eigenfrequency of backlash oscillation is generally said to be situated within the range of $50 \div 100 \mathrm{~Hz}$. Clearances in other running gear components may be the source of additional peaks appearing in the spectra - this includes bearing and axle box guiding clearances. The spectra of longitudinal motion may be influenced by rubber rings in the axle box guiding, which does not affect vertical oscillations.

Fig. 8 shows the measured signals and calculated spectra of the test run numbered M03. In the interval of $10 \div 10.5 \mathrm{~s}$ from the start, the wheelset loses adhesion and the transient phenomenon arises, settling in steady oscillations of lower amplitude while the wheelset is in full sliding. The torque of the traction motor is reduced, as a result of which the adhesion of the wheelset is restored at the time of $13.5 \div 14 \mathrm{~s}$.

\section{Conclusions}

The issues described in the paper were dealt with within the scope of the research project (Lata, Čáp 2007) and partially used in (Lata 2008).

Experimental measurement on an electric locomotive was prepared and performed. The experiment consisted of inducing the transient phenomena of the initiation and termination of gross sliding and of measuring dynamical effects on the selected components of the running gear. The measured data show that the intense development of oscillations occurs at the moments of the beginning and end of wheelset sliding. The relative motion of the wheelset and rail was taken by a high-speed industrial camera by means of which the times of the initiation and termination of sliding were determined and the records were synchronized. The supposition that dynamical effects are most intense at the moments when gross sliding arises and terminates was confirmed. The experiments also displayed the expected features of a drive system with coupled rotational and vertical movements and with the unfavourably soft torque characteristic of a series-wound DC motor.

Interesting results were obtained by a spectral analysis of acceleration signals. The two lowest dominant frequencies are decisively accounted for by the theory, as they equal the eigenfrequencies of a simplified rotor/ wheelset system. The third frequency is related to the eigenoscillation of the gearbox. Higher dominant frequencies may be explained by gear backlash, bearing and axle box guiding clearances and elastic elements in the running gear. 

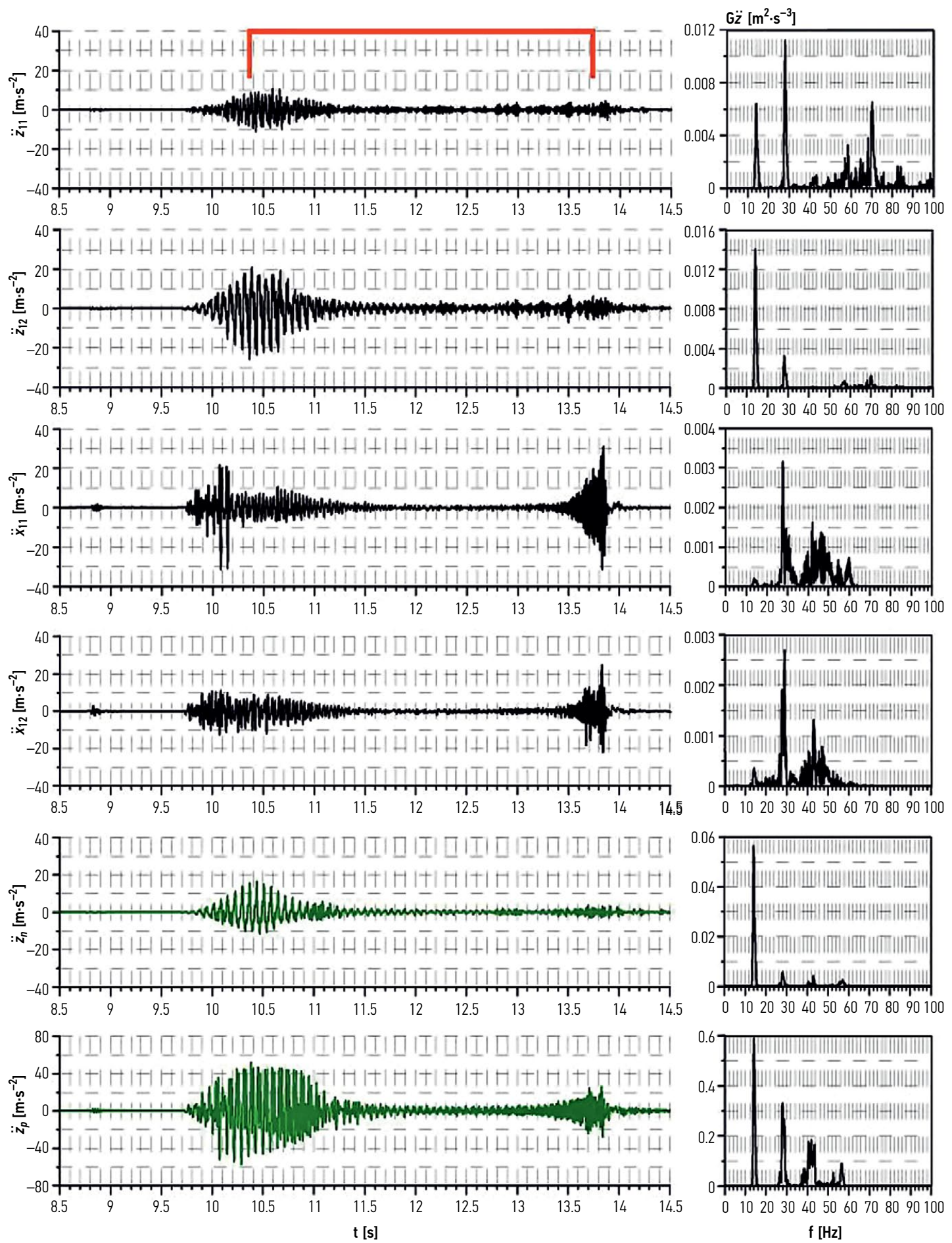

Fig. 8. Acceleration signals measured by the sensors the position of which is indicated in Fig. 3 and their spectral analysis (power spectral densities), experiment M03

\section{Acknowledgement}

The article was written with support provided by VCKV (Research Centre of Railway Vehicles) and financed through the project financing of MŠMT (Ministry of Education, Youth and Sports of the Czech Republic), Registration Number: MŠMT 1M0519.

\section{References}

Buscher, M. 1995. Radschlupfregelung zur maximalen Kraftschlussausnutzung bei elektrischen Traktionsantrieben. Dissertation. Aachen, Deutschland. 288 S. (in German).

Čáp, J. 1991. Otázka pevné a volné vazby kola s kolejnicí, Železniční Technika 21: 176-178 (in Czech).

Freibauer, L. 1983. Adheze kola na vozidlové dráze, in 7. ved. konferencia VŠDS, Žilina, Slovensko, 214-219 (in Czech). 
Hirotsu, T.; Ishida, S. 1975. Adhesion and dynamic phenomena during slippage of electrical rolling stock: 3rd report: self-excited vibration during slippage of electric locomotive trucks, Bulletin of the JSME 18(125): 1236-1245.

Jöckel, A. 2001. Aktive Dämpfung von Ratterschwingungen im Antriebsstrang von Lokomotiven mit Drehstrom-Antriebstechnik, ZEV, DET, Glasers Annalen, Die Eisenbahntechnik 125(5): 191-204 (in German).

Kalker, J. J. 1973. Simplified theory of rolling contact, Delft Progress Report Series C: Mechanical and Aeronautical Engineering and Shipbuilding 1: 1-10.

Kalker, J. J. 1978. Über die Mechanik Kontaktes zwischen Rad und Schiene, ZEV, DET, Glasers Annalen, Die Eisenbahntechnik 102(7/8): 214-218 (in German).

Lata, M. 2008. The modern wheelset drive system and possibilities of modelling the torsion dynamics, Transport 23(2): 172181. http://dx.doi.org/10.3846/1648-4142.2008.23.172-181

Lata, M.; Čáp, J. 2007. Identifikace dynamických jevů, které vznikají v okamžiku vzniku, trvání a zániku prokluzu dvojkolí. Přehledová zpráva č. F4-pz01/2007. 29 p. VCKV, ZČU Plzeň. Projekt MŠMT č. 1M0519. Dopravní fakulta Jana Pernera, Univerzita Pardubice (in Czech).

Lata, M. 2001. The dynamics of locomotive individual drive torsional system, in 18th International Colloquium 'Advanced Manufacturing and Repair Technologies in Vehicle Industry', 20-22 May 2001, Dresden, Deutschland, 71-76 (in English).

Mężyk, A. 2002. Analiza i kształtowanie cech dynamicznych napędów elektromechanicznych: monografia. Gliwice: Wydawnictvo Politechniki Ślaskiej. 114 s. (in Polish).

Polach, O. 2002. Optimierung moderner Lok-Drehgestelle durch fahrzeugdynamische Systemanalyse, EI-Eisenbahningenieur 53(7): 50-57 (in German).

Schreiber, R.; Kögel, R. 1996. Identifikationsmethode zur Bestimmung der Adhäsion zwischen Rad und Schiene, ZEV, DET, Glasers Annalen, Die Eisenbahntechnik 120(2): 48-54 (in German).

Spiryagin, M.; Lee, K. S.; Yoo, H. H. 2008. Control system for maximum use of adhesive forces of a railway vehicle in a tractive mode, Mechanical Systems and Signal Processing 22(3): 709-720.

http://dx.doi.org/10.1016/j.ymssp.2007.09.018

Zahrádka, J. 1976. Dynamika pohonu nápravy při překročení meze adhese, Technické Zprávy ČKD (4): 22-36 (in Czech).

Zeman, V.; Dupal, J.; Hlaváč, Z. 1992. Optimization of mechanical systems parameters in transient vibration, Mechanism and Machine Theory 27(3): 349-356. http://dx.doi.org/10.1016/0094-114X(92)90025-D 